\title{
PENGUKURAN TEKANAN DARAH PADA PASIEN GAGAL JANTUNG KONGESTIF DI INSTALASI RAWAT INAP RUMAH SAKIT ST. ELISABETH SEMARANG
}

\author{
Fef Rukminingsih ${ }^{1}$, Theresia Carolina Susanto ${ }^{2}$ \\ ${ }^{1,2}$ Politeknik Katolik Mangunwijaya \\ Email Korespondensi : fefrukminingsih@gmail.com
}

\begin{abstract}
ABSTRAK
Gagal jantung kongestif (GJK) merupakan salah satu penyakit yang termasuk dalam daftar 10 besar penyakit di Instalasi Rawat Inap RS. St. Elisabeth Semarang. Penyebab terbesar GJK adalah hipertensi. Pasien GJK mendapat terapi antihipertensi untuk mengendalikan tekanan darahnya. Penelitian ini bertujuan untuk mengetahui penurunan tekanan darah pasien GJK dan kesesuaian tekanan darah pasien GJK terhadap target terapinya menurut the Eighth Joint National Committee (JNC VIII) di Instalasi Rawat Inap RS. St. Elisabeth Semarang. Penelitian ini merupakan penelitian deskriptif observasional, menggunakan data retrospektif. Data diambil dari rekam medis pasien GJK yang memperoleh terapi antihipertensi di instalasi rawat inap periode Oktober - Desember 2017, berusia 40 tahun atau lebih, dengan atau tanpa penyakit penyerta. Berdasarkan hasil penelusuran rekam medik diketahui bahwa jumlah pasien GJK yang memenuhi kriteria inklusi sebanyak 60 orang, terdiri dari 30 pasien laki-laki dan 30 pasien perempuan. Sebanyak 35 pasien $(58,33 \%)$ berusia lebih dari 60 tahun. Sebanyak 19 pasien mempunyai penyakit penyerta diabetes mellitus tipe 2 dan atau gagal ginjal kronik. Sebanyak 51 pasien $(85 \%)$ selama rawat inap mengalami rata-rata penurunan TD sistolik sebesar 21,65 $\mathrm{mmHg}$ dan sebanyak 37 pasien (61,67\%) mengalami rata-rata penurunan TD diastolik sebesar 13,38 mmHg. Kesesuaian tekanan darah pasien saat keluar rumah sakit dengan target tekanan darah menurut JNC VIII sebesar 81,67 \%. Dengan demikian progresi perburukan jantung pada sebagian besar pasien GJK dapat dihambat.
\end{abstract}

Kata Kunci : Gagal Jantung Kongestif, , Tekanan Darah, RS St. Elisabeth Semarang 


\title{
BLOOD PRESSURE MEASUREMENT OF INPATIENTS CONGESTIVE HEART FAILURE PATIENTS IN ST. ELISABETH HOSPITAL SEMARANG
}

\begin{abstract}
Congestive heart failure (CHF) is one of the top 10 diseases in the Inpatient of. St. Elisabeth Hospital Semarang. The main cause of CHF is hypertension. CHF patients receive antihypertensive therapy to control their blood pressure. This study aims to determine the decrease in blood pressure of CHF patients and the suitability of blood pressure of CHF patients with their treatment targets according to the Eighth Joint National Committee (JNC VIII) at the Inpatient Installation of St. Elisabeth Hospital Semarang. This research is an observational descriptive study, using retrospective data. Data was taken from medical records of CHF patients in inpatients who received antihypertensive therapy for the period October - December 2017, 40 years or older, with or without concomitant diseases. Based on the results of tracing of medical records it is known that the number of CHF patients who met the inclusion criteria was 60 people, consisting of 30 male patients and 30 female patients. A total of 35 patients $(58.33 \%)$ were aged over 60 years. A total of 19 patients had concomitant diabetes mellitus type 2 and / or chronic kidney failure. A total of 51 patients (85\%) during hospitalization experienced an average reduction in systolic BP of $21.65 \mathrm{mmHg}$ and as many as 37 patients (61.67\%) experienced an average reduction in diastolic BP of $13.38 \mathrm{mmHg}$. The suitability of the patient's blood pressure when leaving the hospital with the target blood pressure according to JNC VIII is $81.67 \%$. Thus the progression of cardiac deterioration in most CHF patients can be inhibited.
\end{abstract}

Keywords : Congestive heart failure, blood pressure, St. Elisabeth Hospital Semarang

\section{PENDAHULUAN}

Gagal jantung merupakan masalah kesehatan masyarakat yang progresif dengan angka morbiditas dan mortalitas yang tinggi. Prevalensi gagal jantung terus meningkat bersamaan dengan bertambahnya usia. Gagal jantung adalah suatu kondisi patologis, dimana jantung sebagai pompa tidak mampu lagi memompakan darah secukupnya dalam memenuhi kebutuhan sirkulasi untuk metabolisme jaringan tubuh, sedangkan tekanan pengisian ke dalam jantung masih cukup tinggi (Panggabean dkk, 2009).
Gagal jantung kongestif (GJK) merupakan salah satu penyakit yang termasuk dalam daftar 10 besar penyakit di Instalasi Rawat Inap RS. St. Elisabeth Semarang. Penyebab terbesar GJK adalah hipertensi (Dipiro et.al., 2008). Terapi GJK bertujuan memperbaiki kualitas hidup dengan mengurangi gejala, memperpanjang usia harapan hidup, dan memperlambat progresi perburukan jantung (Aaronson \& Ward, 2010). Pada pasien GJK, pemberian agen antihipertensi diperlukan untuk mengendalikan tekanan darah dan 
menurunkan tekanan darah sesuai target. Target tekanan darah berdasarkan JNC VIII yaitu pada pasien yang berusia $>60$ tahun adalah < 150/90 mmHg. Target tekanan darah pada pasien yang berusia $\leq 60$ tahun adalah $<140 / 90 \mathrm{mmHg}$. Target tekanan darah pada pasien yang mengalami komplikasi diabetes melitus tipe 2 dan atau kelainan ginjal adalah < 140/90 mmHg (James dkk., 2014). Pencapaian target penurunan tekanan darah sangat diharapkan untuk menghambat progresi perburukan jantung. Selama ini belum pernah dilakukan evaluasi terapi hipertensi terhadap pencapaian target tekanan darah pada pasien GJK di RS St. Elisabeth Semarang. Penelitian ini bertujuan untuk mengetahui penurunan tekanan darah pada pasien GJK dan kesesuaian tekanan darah pasien GJK terhadap target terapinya menurut the Eighth Joint National Committee (JNC VIII) di Instalasi Rawat Inap RS. St. Elisabeth Semarang.

\section{METODE PENELITIAN}

Penelitian merupakan penelitian deskriptif observasional yang menggunakan data retrospektif. Data diperoleh dari rekam medik pasien GJK. Kriteria inklusi penelitian ini adalah pasien GJK yang dirawat inap di RS St. Elisabeth Semarang periode Oktober - Desember 2017 yang mendapat terapi antihipertensi, pasien berusia 40 tahun atau lebih, dengan atau tanpa penyakit penyerta. Kriteria eksklusinya adalah pasien GJK dengan penyakit infeksi. Data yang diambil adalah nomor rekam medik, umur, jenis kelamin, penyakit penyerta, terapi antihipertensi yang diperoleh (jumlah, nama dan dosis obat), lama rawat inap serta data tekanan darah pasien selama dirawat di rumah sakit. Data yang diperoleh kemudian di analisis secara kualitatif dan kuantitatif.

Analisis kualitatif dilakukan
dengan cara mengelompokkan data
berdasarkan karakteristik pasien meliputi
umur, jenis kelamin, jumlah dan jenis
penyakit penyerta, lama rawat inap.
Analisis kuantitatif dilakukan dengan cara
menghitung rata-rata penurunan tekanan
darah pasien selama rawat inap dan
menghitung kesesuaian tekanan darah
pasien terhadap target tekanan darah
menurut JNC VIII (James dkk, 2014).

\section{HASIL DAN PEMBAHASAN}

Berdasarkan hasil penelusuran data rekam medik diketahui sebanyak 60 pasien yang memenuhi kriteria inklusi dan eksklusi. Karakteristik pasien GJK yang menjalani rawat inap di RS St. Elisabeth Semarang periode Oktober-Desember 2017 dapat dilihat pada tabel I.

Jenis kelamin merupakan salah satu faktor yang berpengaruh pada GJK. Lakilaki memiliki resiko gagal jantung $2 \mathrm{x}$ lebih besar dibanding perempuan pada usia 5564 tahun (Pugsley, 2005). Sebelum menopause, perempuan mempunyai risiko lebih kecil terhadap GJK, karena pembuluh darah perempuan dilindungi oleh hormon estrogen. Hormon estrogen meningkatkan rasio high density lipoprotein (HDL) sehingga dapat mencegah terjadinya atherosclerosis (Syamsudin, 2008). Penelitian di RS PKU Muhammadiyah Yogyakarta juga menunjukkan bahwa kejadian GJK lebih banyak pada laki-laki (Hamzah, 2016) tetapi pada penelitian ini jumlah pasien laki-laki dan perempuan sama.

Usia merupakan salah satu faktor yang berpengaruh pada GJK. Semakin 
bertambah usia, risiko terkena penyakit GJK semakin bertambah (Aaronson dan Ward, 2010). Pada penelitian ini sebagian besar pasien GJK berusia > 60 tahun sebesar 58,33\%, hampir sama dengan hasil penelitian di RS PKU Muhammadiyah Gamping Sleman yang menunjukkan pasien GJK yang berusia >60 tahun sebesar 59,38\% (Harigustian dkk, 2016).

Tabel I. Karakteristik pasien Gagal Jantung Kongestif yang menjalani rawat inap di RS St. Elisabeth Semarang periode Oktober-Desember 2017.

\begin{tabular}{lcc}
\hline \multicolumn{1}{c}{ Karakteristik } & Jumlah (orang) & Persentase (\%) \\
\hline Jenis Kelamin & & \\
\hline Laki-Laki & 30 & 50,00 \\
\hline Perempuan & 30 & 50,00 \\
\hline Usia (tahun) & \\
\hline $40-60$ & 25 & 41,67 \\
\hline$>60$ & 35 & 58,33 \\
\hline Penyakit Penyerta & & \\
\hline$\leq 2$ & 25 & 41,67 \\
\hline$>2$ & 35 & 58,33 \\
\hline Jenis Penyakit Penyerta & & 31,67 \\
\hline DM tipe 2 dan atau GGK & 19 & 68,33 \\
\hline Selain DM tipe 2 dan GGK & 41 & \\
\hline Lama Rawat Inap (hari) & & 60,00 \\
\hline$\leq 5$ & 36 & 40,00 \\
\hline$>5$ & 24 &
\end{tabular}

Sebanyak 58,33\% pasien mempunyai lebih dari 2 penyakit penyerta. Hal ini disebabkan karena sebagian besar pasien $(58,33 \%)$ berusia $>60$ tahun. Pada usia lanjut akan muncul penyakit degeneratif dan multipatologik. Penelitian di RSUP dr. M. Djamil Padang menunjukkan bahwa rata-rata jumlah penyakit pada pasien usia lanjut sebanyak 6 penyakit (Pratama dkk, 2017). Jenis penyakit penyerta yang diperhatikan dalam penelitian ini DM tipe 2 dan GGK karena DM tipe 2 dan GGK akan mempengaruhi target terapi tekanan darahnya. Selain itu DM tipe 2 meningkatkan risiko progresivitas pada gagal jantung karena adanya abnormalitas jantung dalam penanganan glukosa dan asam lemak bebas serta adanya efek kerusakan metabolik oleh diabetes pada sistem kardiovaskuler (Rosano dkk, 2017).

Lama rawat inap pasien GJK bervariasi antara 4-21 hari. Penelitian tentang gambaran lama rawat dan profil pasien gagal jantung di Rumah Sakit Cipto Mangunkusumo menunjukkan bahwa ratarata lama rawat inap pasien GJK adalah 89 hari (Djaya dkk, 2015). Dalam penelitian ini sebanyak 24 pasien (40\%) yang lama rawat inapnya lebih dari 5 hari. 
Hasil penelusuran selisih tekanan darah pada saat masuk rumah sakit (MRS) dan keluar rumah sakit (KRS) pasien GJK yang menjalani rawat inap di RS St. Elisabeth Semarang periode OktoberDesember 2017 dapat dilihat pada tabel II.

Sebagian besar pasien (85\%) mengalami penurunan TD sistolik selama rawat inap dan sebanyak $61,67 \%$ pasien mengalami penurunan TD diastolik. Jumlah pasien yang mengalami penurunan TD diastolik lebih sedikit dibandingkan hal ini disebabkan karena jumlah pasien yang berusia $>60$ tahun jumlahnya lebih banyak. Hal ini disebabkan karena faktor predisposisi disfungsi diastolik yang utama adalah usia lanjut, hipertensi dan diabetes mellitus (Rampengan, 2013).

Tabel II. Selisih Tekanan Darah Saat Masuk Rumah Sakit dan Keluar Rumah Sakit Pasien Gagal Jantung Kongestif Yang Menjalani Rawat Inap di RS St. Elisabeth Semarang Periode Oktober-Desember 2017.

\begin{tabular}{lcccccc}
\hline & \multicolumn{7}{c}{ Rata-rata Selisih Tekanan darah } \\
& $\begin{array}{l}\text { Sistolik } \\
(\mathrm{mmHg})\end{array}$ & $\begin{array}{c}\text { Jumlah } \\
(\text { orang) }\end{array}$ & $\begin{array}{c}\text { Persentase } \\
(\%)\end{array}$ & $\begin{array}{c}\text { Diastolik } \\
(\mathrm{mmHg})\end{array}$ & $\begin{array}{c}\text { Jumlah } \\
(\text { orang) }\end{array}$ & $\begin{array}{c}\text { Persentase } \\
(\%)\end{array}$ \\
\hline Turun & 21,65 & 51 & 85,00 & 13,38 & 37 & 61,67 \\
\hline Naik & 8,63 & 8 & 13,33 & 9,95 & 19 & 31,67 \\
\hline Stabil & 0 & 1 & 1,67 & 0 & 4 & 6,66 \\
\hline
\end{tabular}

Kesesuaian tekanan darah pasien GJK di Instalasi Rawat Inap RS. St. Elisabeth Semarang terhadap target tekanan darah menurut JNC VIII dapat dilihat pada tabel III.

Tabel III. Kesesuaian Target Tekanan Darah Dengan JNC VIII Pasien Gagal Jantung Kongestif yang menjalani rawat inap di RS St. Elisabeth Semarang periode Oktober-Desember 2017

\begin{tabular}{lcc}
\hline \multicolumn{1}{c}{ Kesesuaian } & Jumlah (orang) & Persentase $(\%)$ \\
\hline Sesuai & 49 & 81,67 \\
\hline Tidak Sesuai & 11 & 18,33 \\
\hline Jumlah & 60 & 100,00 \\
\hline
\end{tabular}

Penggunaan terapi agen antihipertensi pada pasien gagal jantung kongestif dapat menurunkan tekanan darah sesuai dengan target tekanan darah menurut JNC VIII pada 49 pasien $(81,67 \%)$. Ketidaksesuaian penurunan dengan target tekanan darah dapat dipengaruhi oleh banyak faktor, seperti jumlah dan jenis penyakit penyerta, ketepatan pemilihan agen antihipertensi dan dosisnya (Chobanian dkk., 2003). Berdasarkan Tabel III diketahui sebanyak 11 pasien tidak tercapai target tekanan darahnya. Dari 11 pasien tersebut diketahui mempunyai TD sistolik normal atau mendekati normal tetapi mengalami disfungsi diastolik. Pada disfungsi diastolik, relaksasi miokard yang 
berkepanjangan dan peningkatan kekakuan (yang menurunkan tingkat pengisian dan volume) meningkatkan tekanan diastolik ventrikel kiri dan mengurangi isi sekuncup saat istirahat dan selama bekerja. Akibatnya, terjadi gagal jantung (Imaligy, 2014). Penelitian Tambuwun dkk (2016) menunjukkan bahwa pada pasien gagal jantung dengan hipertensi yang tersering ditemukan ialah gagal jantung diastolik.

\section{SIMPULAN}

Kesimpulan dari penelitian ini adalah :

1. Dari 60 pasien GJK diketahui sebanyak 51 pasien $(85 \%)$ mengalami rata-rata penurunan TD sistolik sebesar 21,65 $\mathrm{mmHg}$ dan sebanyak 37 pasien $(61,67 \%)$ mengalami rata-rata penurunan TD diastolik sebesar 13,38 mmHg.

2. Kesesuaian tekanan darah pasien saat keluar rumah sakit dengan target tekanan darah menurut JNC III sebesar 81,67 \%. Dengan demikian progresi perburukan jantung pada sebagian besar pasien GJK di RS St. Elisabeth Semarang dapat dihambat.

\section{UCAPAN TERIMA KASIH}

Pada kesempatan ini, peneliti ingin mengucapkan terima kasih kepada Direktur Politeknik Katolik Mangunwijaya Semarang yang telah mendukung pembiayaan dalam penelitian ini.

\section{DAFTAR PUSTAKA}

Aaronson, PI dan Ward, JPT., 2010. At Glance Sistem Kardiovaskular (ketiga). Jakarta: Erlangga.
Chobanian, MD., 2003. The Seventh Report of the Joint National Committee on Prevention,

Detection, Evaluation, and Treatment of High Blood Pressure. National Institutes of Health.

Djaya, KH., Nasution, SA., Antono, D., 2015, Gambaran Lama Rawat dan Profil Pasien

Gagal Jantung di Rumah Sakit Cipto Mangunkusumo. Indonesian Journal of CHEST Crit and Emerg Med., 2(4), 141-150.

Hamzah, Rori., 2016, Hubungan usia dan jenis kelamin dengan kualitas hidup pada penderita

gagal jantung di RS PKU Muhammadiyah Yogyakarta. http://digilib.unisayogya.ac.id/2256 I1/NASKAH $\% 20$ PUBLIKASI\%20 \%28RORI\%20HAMZAH\%29.pdf diakses tanggal 31 Oktober 2019.

Harigustian, Yayang., Dewi, Arlina., Khoiriyati, Azizah., 2016, Gambaran Karakteristik

Pasien Gagal Jantung Usia 45-65

Tahun di Rumah Sakit PKU Muhammadiyah Gamping Sleman. Indonesian Journal of Nursing Practices, 1(1), 55-60.

Imaligy, Ervinaria Uly., 2014, Gagal Jantung pada Geriatri, CDK-212., 41(1), 19-24.

James, P.A., Oparil, S., Carter, B.L., Cushman, W.C., DennisonHimmelfarb, C., Handler, J., Ortiz, E., 2014, Evidence-Based Guidline for the Management of High Blood Pressure in Adults: (JNC8), Jama, 311(5), 507-20. 
Panggabean, MM., Sudoyo, AW.,

Setiyohadi, B., Alwi, I., Simadibrata, M.,

Setiati, S., 2009,

Gagal jantung. Buku Ajar Penyakit

Dalam, Ed.5. Jakarta: Interna Publishing, 1586.

Pratama, EL., Martini, RD., Pertiwi, D., 2017, Gambaran Multipatologi Pasien Geriatri di Poliklinik Khusus Geriatri RSUP dr. M. Djamil Padang Periode JanuariDesember 2014, Jurnal Kesehatan Andalas, 6(3), 536545.

Pugsley, MK., 2005, Cardiac Drug Development Guide. Springer: New Jersey.

Rampengan, Starry H., 2013, Penanganan Gagal Jantung Diastolik. Jurnal Biomedik, 5(1), 1-9.

Rosano, GM., Vitale, C., Seferovic, P., 2017, Heart Failure in Patients with Diabetic Mellitus. Card Fail Rev, 3(1), 52-55.

Syamsudin., 2008, Buku Ajar Farmakoterapi Kardiovaskular dan Renal,Salemba Medika Jakarta Selatan.

Tambuwun, CFD., Panda, AL., Rampengan, SH., 2016, Gambaran pasien gagal jantung dengan penyakit hipertensi yang menjalani rawat inap di RSUP Prof. Dr. R.D. Kandou Manado periode September-November 2016, Jurnal e-Clinic, 4(2). 